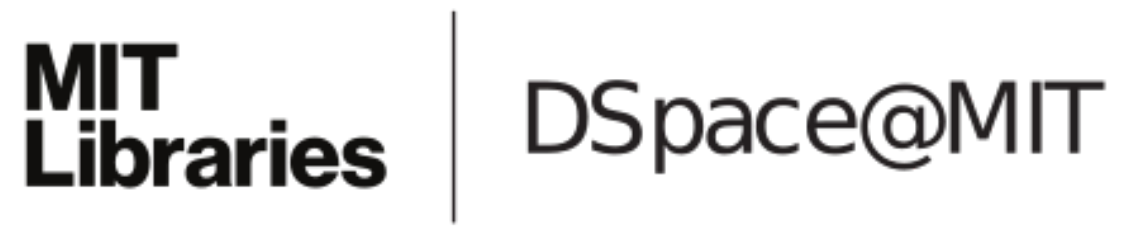

\author{
MIT Open Access Articles
}

Screening Oxide Support Materials for OER Catalysts in Acid

The MIT Faculty has made this article openly available. Please share how this access benefits you. Your story matters.

Citation: Han, Binghong et al., "Screening Oxide Support Materials for OER Catalysts in Acid." Journal of The Electrochemical Society 165, 10 (July 2018): F813-F820 (c2018 Authors

As Published: https://dx.doi.org/10.1149/2.0921810JES

Publisher: The Electrochemical Society

Persistent URL: https://hdl.handle.net/1721.1/128106

Version: Final published version: final published article, as it appeared in a journal, conference proceedings, or other formally published context

Terms of Use: Article is made available in accordance with the publisher's policy and may be subject to US copyright law. Please refer to the publisher's site for terms of use. 


\title{
Screening Oxide Support Materials for OER Catalysts in Acid
}

\author{
Binghong Han, $₫ 1, a, z$ Marcel Risch, ${ }^{2, b}$ Samuel Belden, ${ }^{1}$ Seonggyu Lee, ${ }^{3}$ Domnik Bayer, ${ }^{4}$ \\ Eva Mutoro, ${ }^{4}$ and Yang Shao-Horn ${ }^{1} 1,2, *, \mathrm{z}$ \\ ${ }^{I}$ Department of Materials Science and Engineering, Massachusetts Institute of Technology, Cambridge, Massachusetts \\ 02139, USA \\ ${ }^{2}$ Research Laboratory of Electronics, Massachusetts Institute of Technology, Cambridge, Massachusetts 02139, USA \\ ${ }^{3}$ Department of Chemical Engineering, Pohang University of Science and Technology, Pohang, 790-784, Korea \\ ${ }^{4}$ BASF SE, 67056 Ludwigshafen am Rhein, Germany
}

\begin{abstract}
The lack of stable and economic supporting materials at high voltages hampers the development of electrocatalysts for oxygen evolution reaction (OER), which is the major source of energy loss in water splitting to produce hydrogen. In this work, we developed systematic methods to evaluate candidate compounds that can potentially replace traditional carbon support for OER catalysts. Stability, economic and conductivity criteria of the oxide support materials were studied and discussed. A nano-sized antimony-doped tin oxide was fabricated to support $\mathrm{RuO}_{2}$, which was shown to provide the highest stability and activity of OER in $0.5 \mathrm{M} \mathrm{H}_{2} \mathrm{SO}_{4}$ up to $2.5 \mathrm{~V}_{\mathrm{RHE}}$ and up to $55^{\circ} \mathrm{C}$.

(C) 2018 The Electrochemical Society. [DOI: 10.1149/2.0921810jes]
\end{abstract}

Manuscript submitted April 4, 2018; revised manuscript received June 13, 2018. Published July 20, 2018.

Developing new electrochemical energy storage and conversion devices with higher energy efficiency and energy density is important for the application of sustainable new energy sources. However, the slow kinetics of oxygen evolution reaction (OER) causes great energy loss in many electrochemical devices, including water splitting electrolyzers $^{1-4}$ and rechargeable metal-air batteries. ${ }^{5-8}$ To overcome the slow kinetics of OER and improve the efficiency of energy storage devices, precious-metal oxide catalysts such as $\mathrm{RuO}_{2}$ and $\mathrm{IrO}_{2}$ have been widely used in both acid and basic solutions, ${ }^{9,10}$ which suffer from high cost and low elemental abundance. Recently, various non-precious-metal oxides have been developed as the nextgeneration OER catalysts with high and stable OER activity in basic electrolytes, ${ }^{7,8,11-13}$ however they are not stable in acid solutions. Currently, the acidic electrolyte is still widely used in the industrial applications such as the polymer electrolyte membrane (PEM) water electrolyzer, which has the advantages of high operation current, high voltage efficiency, compact system design, etc. ${ }^{14}$ For the applications using acidic electrolytes, to reduce the cost of precious-metal oxides as the OER catalysts, researchers are developing $\mathrm{IrO}_{2}$-based and $\mathrm{RuO}_{2}$-based nanoparticles (NPs) with high surface area-to-mass ratios. ${ }^{9}$ At the same time, distributing the catalyst NPs on the stable and conductive support materials can help to prevent the aggregation of catalyst NPs, provide higher electrical conductivity, and therefore maximize the effective catalytic surface area exposed to the electrolyte, which are important for the enhancement of mass activities of the precious-metal oxide OER catalysts. ${ }^{15-18}$ Currently, mesoporous carbon and their nanostructured analogs (e.g. carbon nanotubes) are widely used as the catalyst supports because of their low costs, high conductivities, large surface areas, and relatively high chemical and electrochemical stabilities in low-voltage applications such as fuel cells. ${ }^{19-23}$ However, electrolyzers and other electrochemical techniques that involve OER are usually driven in acid electrolyte up to $2.0 \mathrm{~V}$ versus the reversible hydrogen electrode $\left(\mathrm{V}_{\mathrm{RHE}}\right)$ to gain enough current density. ${ }^{24}$ Under such highly oxidative voltage, carbon materials become unstable and can be oxidized into $\mathrm{CO}_{2}$, causing severe degradation of the electrode during OER. ${ }^{24}$ Therefore, no support or only non-conductive $\mathrm{TiO}_{2}$ support was used in traditional electrolyzers, which caused higher loadings of expensive OER catalysts. ${ }^{25}$ Recently, several oxide materials have been studied as stable and conductive supports under high-voltage (i.e. highly oxidative) conditions for electrolyzers, including $\mathrm{Ti}_{\mathrm{n}} \mathrm{O}_{2 \mathrm{n}-1},{ }^{26} \mathrm{TiC},{ }^{27} \mathrm{SiC}$ -

\footnotetext{
*Electrochemical Society Fellow.

${ }^{\text {a}}$ Present address: Argonne National Laboratory, Chemical Science and Engineering Division, Lemont, Argonne, Illinois 60439, USA.

${ }^{\mathrm{b}}$ Present address: University of Goettingen, Institute of Materials Physics, 37077 Göttingen, Germany.

zE-mail: binghong.han@anl.gov; shaohorn@mit.edu
}

$\mathrm{Si}^{28}{ }^{28} \mathrm{SnO}_{2}{ }^{16,29}$ and their fluorine-doped ${ }^{30}$ or antimony-doped ${ }^{17,31-34}$ forms. However, there lacks a systematic stability test of a wide spectra of candidate support materials in acid electrolyte under the OER operational condition. In addition, there lacks a deep investigation of the formal criteria for support material selection covering the cost, conductivity, stability, and other characters of the candidate materials, which is highly desirable in order to facilitate the development of long-lived catalyst supports used in acidic conditions such as those in PEM electrolyzers.

In this work, we systematically studied a number of commercial and synthesized oxide materials as OER catalyst supports, where their conductivity, electrochemical stability, and activity improvement effect to OER catalysts were compared. Among all the commercial materials screened, antimony-doped tin oxide (ATO) showed a reasonable cost, a high conductivity, and a high stability, which makes it the most promising candidate for the next-generation support materials. In addition, we synthesized nano-sized ATO particles using a sol-gel method, which showed smaller particle size, higher conductivity, and greater improvement to on electrochemical surface area compared with the commercial ATO when supporting $\mathrm{RuO}_{2}$ to catalyze OER in acid electrolytes. The OER activity and stability of $\mathrm{RuO}_{2}$ NPs supported by the sol-gel synthesized ATO surpassed those supported by the commercial ATO, the high-surface-area carbon, or the other support materials in previous studies.

\section{Experimental Methods and Materials}

Materials selection.-To find support materials that could replace carbon, we looked for materials that are stable at $\mathrm{pH} 0$ and above $2.0 \mathrm{~V}_{\mathrm{RHE}}$. A common tool to predict the stability of the materials is a Pourbaix diagram, which uses thermodynamic properties to determine the stability of various species at certain $\mathrm{pH}$ and voltage. After filtering all the transition metal oxides with the criteria that the stable region of the oxide should cover the $2.0 \mathrm{~V}_{\mathrm{RHE}}$ at $\mathrm{pH} 0$ on Pourbaix diagrams provided by the materials project (www.materialsproject.org), the following oxides were found to be stable: $\mathrm{MoO}_{3}, \mathrm{RuO}_{2}, \mathrm{Sb}_{2} \mathrm{O}_{5}, \mathrm{TeO}_{3}$, $\mathrm{WO}_{3}, \mathrm{OsO}_{4}, \mathrm{PtO}_{2}, \mathrm{IrO}_{2}, \mathrm{Nb}_{2} \mathrm{O}_{5}, \mathrm{ZrO}_{2}, \mathrm{Ta}_{2} \mathrm{O}_{5}, \mathrm{HfO}_{2}$. Moreover, we have the following oxides whose stability region is close to $2.0 \mathrm{~V}_{\mathrm{RHE}}$ at $\mathrm{pH} 0$, and therefore are potentially stable: $\mathrm{TiO}_{2}, \mathrm{MnO}_{2}, \mathrm{Cu}_{2} \mathrm{O}_{3}$, $\mathrm{GeO}_{2}, \mathrm{AgO}, \mathrm{SnO}_{2}, \mathrm{Tl}_{2} \mathrm{O}_{3}, \mathrm{PbO}_{2}, \mathrm{Bi}_{4} \mathrm{O}_{7}$. Here the materials project is only used for the initial selection and screening of stable oxides under acidic OER conditions. Some candidates listed here, such as $\mathrm{RuO}_{2}$, could be actually instable under the real OER condition. ${ }^{35-37}$ The true instability of these candidates still need experimental examinations, which will be described in the later session of electrochemical stability test. In the next step, we compared the cost of these materials to further shorten the candidate list. Figure S1 in the 
Table I. Basic properties of the materials used in this work.

\begin{tabular}{|c|c|c|c|c|}
\hline Compound & Provider or synthesis method & BET surface area $\left(\mathrm{m}^{2} / \mathrm{g}\right)$ & Particle size $(\mathrm{nm})$ & Conductivity $(\mathrm{mS} / \mathrm{cm})$ \\
\hline FTO Glass & Sigma Aldrich & - & - & - \\
\hline Commercial ATO (ATO-C) & Alfa Aesar & 66.3 & $11.4 \pm 4.5$ & 5 \\
\hline Synthesized ATO (ATO-S) & Sol-gel method & 89.8 & $3.6 \pm 1.0$ & 20 \\
\hline $\mathrm{WO}_{3}$ & Alfa Aesar & 19.4 & $67.5 \pm 41.5$ & $2.1 \times 10^{-9}$ \\
\hline $\mathrm{TiCN}$ & Alfa Aesar & 21.2 & $41.8 \pm 24.6$ & 51 \\
\hline $\mathrm{MoO}_{2}$ & Alfa Aesar & 5.7 & $247 \pm 150$ & 120 \\
\hline $\mathrm{MoO}_{3}$ & Sigma Aldrich & 0.24 & $2946 \pm 1645$ & $1.0 \times 10^{-4}$ \\
\hline $\mathrm{Na}_{2} \mathrm{MoO}_{4}$ & Alfa Aesar & 0.33 & $1787 \pm 1636$ & 0.03 \\
\hline XC-72 Carbon & Fuel Cell Earth & - & - & 1250 \\
\hline AB Carbon & Chevron & - & - & 245 \\
\hline $\mathrm{IrO}_{2}$ & Alfa Aesar & 22.0 & $19.2 \pm 7.9$ & 1010 \\
\hline $\mathrm{RuO}_{2}$ & Sigma Aldrich & 16.2 & $28.7 \pm 10.2$ & 520 \\
\hline $\mathrm{MnO}_{2}$ & Alfa Aesar & 19.7 & $51.4 \pm 38.5$ & $5.0 \times 10^{-3}$ \\
\hline $\mathrm{TiO}_{2}$ & Alfa Aesar & 11.9 & $46 \pm 12$ & $5.2 \times 10^{-9}$ \\
\hline
\end{tabular}

Supplementary Information (SI) showed the prices of elements ${ }^{38}$ whose oxides are stable or potentially stable. The prices of some elements are low enough (shadowed in green region) to be used as major components for possible support materials while some are expensive (shadowed in yellow region), which might be used as minor components.

Materials preparation.-In this study, both commercial materials and sol-gel synthesized oxides were employed. The commercial materials include fluorine doped tin oxide (FTO) glass, $\mathrm{MoO}_{3}$ and $\mathrm{RuO}_{2}$, from Sigma Aldrich; ATO, $\mathrm{IrO}_{2}, \mathrm{MoO}_{2}, \mathrm{TiO}_{2}, \mathrm{MnO}_{2}, \mathrm{Na}_{2} \mathrm{MoO}_{4}$, TiCN and $\mathrm{WO}_{3}$ from Alfa Aesar; XC-72 carbon from Fuel Cell Earth; and Acetylene Black $(\mathrm{AB})$ carbon from Chevron. In this paper the commercial ATO is denoted as ATO-C. We also synthesized nanosized ATO with $14 \%$ Sb doping using a sol-gel method (denoted as ATO-S), which included the following steps. First, $1.28 \mathrm{ml}$ of $37 \%$ $\mathrm{HCl}$ was slowly added to the mixture of $0.2 \mathrm{~g}$ antimony (III) ethoxide and $2.88 \mathrm{~g}$ tin (IV) tert-butoxide under vigorous stirring. Second, the mixture was stirred at $80^{\circ} \mathrm{C}$ for $1 \mathrm{~h}$ and the solvent was evaporated at $60^{\circ} \mathrm{C}$. Third, ATO particles were annealed in Air under $100 \mathrm{ml} / \mathrm{min}$ flow at $500^{\circ} \mathrm{C}$ for $3 \mathrm{~h}$ to remove organics left on the surface of the particles and improve the crystallinity. The crystal structures of the ATO-S and ATO-C were characterized by X-ray diffraction (XRD) using a PANalytical X'Pert Pro powder diffractometer in the Bragg-Brentano geometry using a Copper $\mathrm{K} \alpha$ radiation, where data were collected using the $X^{\prime}$ Celerator detector in the $8-80^{\circ}$ window in the $2 \theta$ range. The ATO-S particles showed the anatase phase in XRD and a high crystallinity in TEM, with the Sb doping level of $\sim 14 \%$, similar to the ATO-C. The specific surface area of each candidate support material was determined using Brunauer, Emmet and Teller (BET) analysis on a Quantachrome ChemBET Pulsar from a single-point BET analysis performed after $12 \mathrm{~h}$ outgassing at $150^{\circ} \mathrm{C}$. A table of the materials used in this study can be found in Table I.

Conductivity measurement.-We developed a measurement setup shown in Figure 1a to compare the electronic conductivity of support materials systematically. First, the material powders were weighted and loaded into the black plastic cell. Then two metal cylinder dies were used to lock the powders inside the cell. These two metal dies also work as the positive and negative electrodes for conductivity measurement. Impedance spectroscopy was used to measure the voltage and current applied between the metal dies under the frequency when the sample powders in the cell act as a pure resistor (with phase close to 0 during impedance measurement). During the conductivity measurement, increasing pressure was gradually applied between the two dies, which gradually compresses the powders into a condensed pellet. The pressure was controlled below 1.6 MPa. The resistance change can be recorded as a function of pressure, as shown in Figure 1b. When the pressure is high enough, the resistance becomes a roughly constant number $Z$, which was used to calculate the conductivity $\sigma$ of the materials.

From the classic conductivity relationship without any porosity correction, we have:

$$
|Z|=\frac{l}{S \sigma}
$$

where $l$ is the distance between two metal dies that can be measured at the end of the measurement, and $S$ is the cross-section area of the die that can be calculated as $S=\pi r^{2}$. Here $r$ is the radius of the die.

However, even under the highest pressure applied in this study, the porosity $f$ of the material is still high $(\sim 10-40 \%$, depending on materials), which leads to a much smaller conductivity measurement that needs to be corrected. In this study, the following factor $\alpha$ is used as an approximated porosity correction: ${ }^{39}$

$$
\alpha=\mathrm{e}^{b f}
$$

Here $f$ could be calculated by $f=\frac{l s-\frac{m}{\rho}}{l s}$, where $m$ is the mass of the loaded powder, and $\rho$ is the density of the material. $b \approx 3$ for the spherical pore approximation. ${ }^{39}$ And the corrected conductivity can be written as:

$$
\sigma=\frac{\alpha l}{|Z| \pi r^{2}}=\frac{l}{|Z| \pi r^{2}} \mathrm{e}^{b \frac{\rho l \pi r^{2}-m}{\rho l \pi r^{2}},}
$$

Electrochemical stability test.--In this study, FTO glass was used as the substrate of supporting materials for the stability measurements because FTO itself showed higher stability in acid electrolyte under high oxidizing voltages compared with the traditional support, Ti foil. The stabilities of pure FTO glass and Ti foil in acid electrolyte were measured and compared in Figure S2. After holding at $2.0 \mathrm{~V}_{\mathrm{RHE}}$ for $1 \mathrm{~h}$, FTO glass showed less capacitance change than the untreated Tifoil. In addition, the ATO-C loaded on FTO (ATO-C@FTO) showed less capacitance change than ATO-C loaded on Ti foil (ATO-C@Ti), implying that FTO is a better substrate to support and test the candidate materials. Therefore, in this study we will only use FTO as our substrate for the stability measurement.

To measure the stability of different support materials, $10 \mathrm{mg}$ of sample powder was first added into the mixed solution of $2.35 \mathrm{ml}$ de-ionized water, $0.586 \mathrm{ml}$ isopropanol, and $3.81 \mu 15 \mathrm{wt} \%$ Nafion solution to make the ink solution. Then after ultra-sonication for $30 \mathrm{~min}$, $30 \mu \mathrm{l}$ of the ink solution was distributed onto the conductive side of a clean $1 \mathrm{~cm}^{2}$ FTO glass. The final loading of candidate support material on FTO glass is $100 \mu \mathrm{g} / \mathrm{cm}^{2}$ glass. The FTO glass was precleaned by first ultra-sonication in de-ionized water for $15 \mathrm{~min}$ and then ultra-sonication in ethanol for another 15 min before ink dropcasting. After drying the ink in air for $12 \mathrm{~h}$, the FTO glass with the sample material was immersed into Ar-saturated $0.5 \mathrm{M} \mathrm{H}_{2} \mathrm{SO}_{4}$ solution in a three-electrode electrochemical cell, which is shown in the Figure S3. The FTO glass was connected to potentiostat using a clip, 
acting as the working electrode. All connections between FTO glass and potentiostat were covered by paraffin wax (Sigma Aldrich) to prevent etching of these parts by the acidic electrolyte. $\mathrm{Ag} / \mathrm{AgCl}$ electrode was used as the reference electrode, and Pt wire as the counter electrode. The measured voltages were converted to RHE scale using $\mathrm{H}_{2} / \mathrm{H}^{+}$redox couple. A glass jacket outside the glass cell was used to circulate heated or cooled water in controlling the temperature of the electrolyte. The capacitance of the working electrode was measured using cyclic voltammetry $(\mathrm{CV})$ measurements at $100 \mathrm{mV} / \mathrm{s}$ from 0.5 to $0.7 \mathrm{~V}_{\mathrm{RHE}}$ in Ar-saturated $0.5 \mathrm{M} \mathrm{H}_{2} \mathrm{SO}_{4}$ electrolyte. This potential range is selected because most of the tested materials are electrochemically stable in this region with no OER or metal redox reactions that may affect the measurement of double-layer capacitance. The integration of total charge transfer in one $\mathrm{CV}$ cycle was divided by the corresponding voltage change (i.e. $0.2 \mathrm{~V}$ ) to calculate the capacitance.

Two different voltage-holding methods were applied as the stability test in this study. One method, the simple voltage holding method, is to keep the working electrode at certain voltage for a continuous period, as shown in Figure S4a. The other method is called start-stop test, which switches the working electrode between a certain voltage and the open circuit voltage for $1 \mathrm{~min}$ at each voltage stage, as shown in Figure S4b. The capacitance measurement showed that the degradation of ATO-C@FTO is similar as a function of total voltage holding time in both methods (Figure S4c), implying that the voltage shift does not have clear acceleration effect to the degradation of the material. Therefore, we will only apply the voltage holding method for the stability measurement in this study.

Selected supporting materials were mixed with $\mathrm{RuO}_{2}$ for the OER activity measurement and were deposited onto the FTO glass using the same ink drop-cast method mentioned above. The supporting material loading was $100 \mu \mathrm{g} / \mathrm{cm}^{2}$ glass, and the $\mathrm{RuO}_{2}$ loading was also $100 \mu \mathrm{g} / \mathrm{cm}^{2}$ glass. The OER activities were measured by $\mathrm{CV}$ at $10 \mathrm{mV} / \mathrm{s}$ from 0.5 to $1.7 \mathrm{~V}_{\mathrm{RHE}}$ in $\mathrm{O}_{2}$-saturated $0.5 \mathrm{M} \mathrm{H}_{2} \mathrm{SO}_{4}$ electrolyte and the currents at $1.5 \mathrm{~V}_{\mathrm{RHE}}$ were used for comparison. It is worth noticing that when conductive materials were loaded on the FTO glass, the ohmic resistance of the electrochemical test setup measured using the impedance method was between 15 and $20 \Omega$, with the measured current less than $3 \mathrm{~mA}$. The corresponding iR drop was between 45 to $60 \mathrm{mV}$, whose difference among samples is negligible in the stability and OER activity tests.

Transmission electron microscopy.-Transmission Electron Microscopy (TEM) samples were prepared by dropping catalyst ink onto $\mathrm{Cu}$ grids or using grids to scratch the working electrode after OER measurements. TEM images in this work were taken on JEOL 2010F equipped with ultrahigh resolution polepiece, having a point resolution of $0.19 \mathrm{~nm}$. Bright field diffraction contrast imaging was used to determine particle size distributions and general morphology of the catalyst nanoparticles. Digital images were analyzed using Gatan Digital Micrograph v2.01 (Gatan Inc.) and ImageJ v1.44p (National Institute of Health, USA). High resolution TEM (HRTEM) images were recorded without an objective aperture and were analyzed using Gatan Digital Micrograph. Parallel-beam energy dispersive spectroscopy (EDS) data were collected and the atomic composition was determined using INCA (Oxford Instruments) software. For each oxide sample, three different spots with a diameter of $\sim 200 \mathrm{~nm}$ were used to collect the bulk chemical composition, while three different spots with a diameter of $\sim 5 \mathrm{~nm}$ at the particle edges were used to collect the surface chemical composition. Error bars in all EDS data represent the standard deviation of the results on multiple spots. TEM images are also used in this study to determine the particle size distributions for each candidate powder. For each sample, at least 100 particles were measured to calculate the average size and the standard deviation of the particle diameter, and the results were shown in Table I.

\section{Results and Discussion}

Electrical conductivity and electrochemical capacitance measurements of candidate support materials.-Support materials must be electrical conductive to transfer the electrons during the OER in order to increase the effective electrochemical surface area. The correct conductivity measurement of supporting materials is important but challenging, since the supporting materials are in particle form with low pack density. In this paper, we specifically developed a conductivity measurement setup for the powder samples, as shown in Figure 1a, to compare the electronic conductivity of support materials systematically. The detailed measurement principle can be found in the experimental method section and in the SI. We found that the electrical conductivity is closely related to the effective electrochemical surface area. Here the effective electrochemical surface area of the candidate support material was evaluated by the measurement of electrochemical capacitance, ${ }^{4,40}$ which was calculated using the $\mathrm{CV}$ curve measured at $100 \mathrm{mV} / \mathrm{s}$ from 0.5 to $0.7 \mathrm{~V}_{\mathrm{RHE}}$ in Ar-saturated $0.5 \mathrm{M} \mathrm{H}_{2} \mathrm{SO}_{4}$ electrolyte with the oxide loading of $100 \mu \mathrm{g} / \mathrm{cm}^{2}$ glass. As shown in Figure 1c, when the measured conductivity was lower than $1 \mathrm{mS} / \mathrm{cm}$, the measured capacitance is almost the same to the pure FTO substrate, indicating that the candidate compounds particles contribute almost no additional electrochemical effective area. This is because low conductivity will make it hard to transfer electrons to the (a)

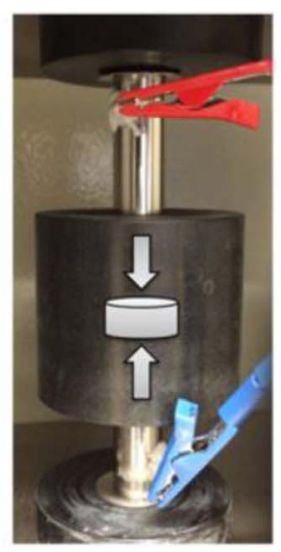

(b)

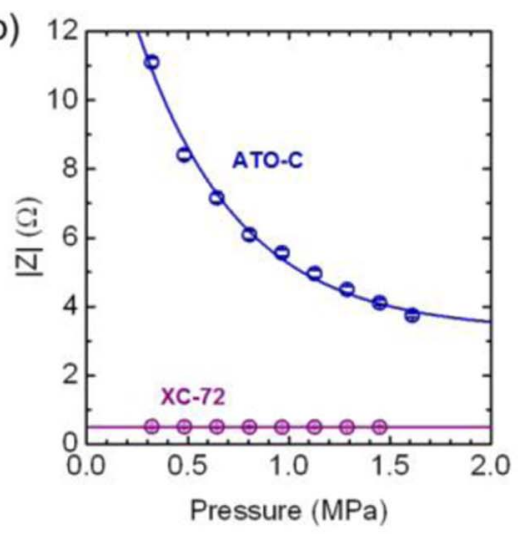

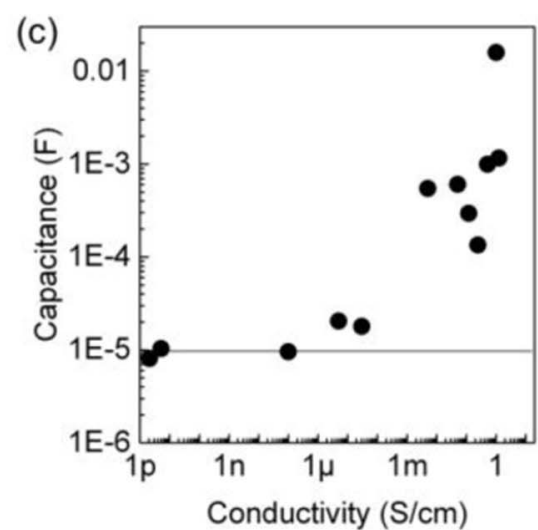

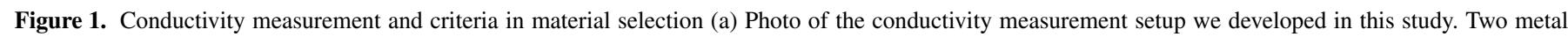

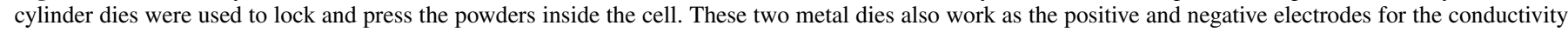

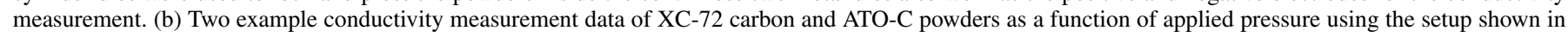

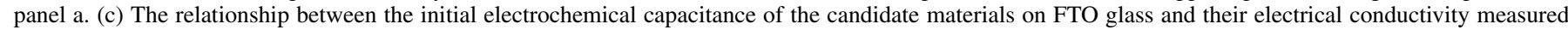

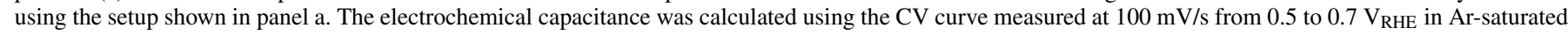
$0.5 \mathrm{M} \mathrm{H}_{2} \mathrm{SO}_{4}$ electrolyte. The horizontal line represents the capacitance of pure FTO glass. 
surface of the candidate particles as the currents will take the path of least resistance, and therefore most of the surface area will be inert during electrochemical processes. Hence, materials with conductivity lower than $1 \mathrm{mS} / \mathrm{cm}$ will not be suitable as support materials.

In addition to the high conductivity, the support materials for OER catalysts in acidic electrolytes also require reasonable stability when holding at a highly oxidative potential in the acid solution. In this study, the stability of candidate oxide supports was evaluated by measuring the capacitance change before and after a potential holding at $2.0 \mathrm{~V}_{\mathrm{RHE}}$ in the Ar-saturated $0.5 \mathrm{M} \mathrm{H}_{2} \mathrm{SO}_{4}$ for $1 \mathrm{~h}$. Here the $2.0 \mathrm{~V}_{\mathrm{RHE}}$ voltage holding is selected to develop a protocol for accelerated stability tests, which is as high as or higher than the voltages applied in previous stability studies on support materials. ${ }^{24,26-34}$ The corresponding current change during the voltage holding on example materials can be found in Figure S5. Figures $2 \mathrm{a}-2 \mathrm{~d}$ showed the evolutions of CV curves before and after the voltage holding on 4 example materials. In the case of XC-72 carbon, the double-layer capacitance reduced notably after the voltage holding (see Figure $2 \mathrm{a}$ ), implying the severe degradation of carbon supports under the highly oxidative conditions. Similar stability issue has been observed in a previous study, ${ }^{24}$ and is the main motivation for the development of more stable non-carbon supports. ${ }^{26-29}$ In comparison, the CV curve of the ATO-C sample remain almost unchanged after the same voltage holding, indicating a higher stability under the OER condition in the acid solution (see Figure $2 b$ ). The stability of the ATO under high voltages in acid electrolyte has been previously reported by Geiger et al., ${ }^{30}$ with a high onset overpotential for reductive and oxidative dissolution of more than $0.4 \mathrm{~V}$. Some of the candidate materials with high conductivity, such as $\mathrm{MoO}_{2}$ and TiCN, were found even less stable than the carbon materials ( $\mathrm{AB}$ carbon and $\mathrm{XC}-72$ ) after holding the voltage at 2.0 $\mathrm{V}_{\mathrm{RHE}}$ (see Figures $2 \mathrm{c}$ and $2 \mathrm{~d}$ ). Figure 2e summarizes the capacitance of all the commercial candidate supports before and after the $1 \mathrm{~h}$ voltage holding. From Figure 2e, we found that ATO-C demonstrated the highest stability and highest electrochemical surface area among all the nonprecious-metal compounds, only lower than $\mathrm{IrO}_{2}$ and $\mathrm{RuO}_{2}$. Due to the high cost of Ir and Ru, ATO was considered the best support material among all candidates based on the stability, conductivity and economic criteria.

The ATO-C powder used in this study has an average particle size of $\sim 11.4 \mathrm{~nm}$ (see Figure $3 \mathrm{~b}$ ). To test how the change of particle size would influence the performance of ATO as support material, we synthesized some smaller ATO particles (ATO-S) using the sol-gel method, with the average particle size of $\sim 3.6 \mathrm{~nm}$ (see Figure 3a). The XRD results showed that the ATO-S particles have the same anatase phase as the ATO-C. The EDS results demonstrated that the synthesized ATO-S has a Sb doping level $\sim 14 \%$, similar to that of ATO-C. This means ATO-S and ATO-C have similar chemistry and atomic structure. The main difference of ATO-S from ATO-C is its smaller particle size, which is accompanied by a higher surface area. Although the increased grain boundaries in smaller particles usually lead to lower conductivity, here we found that the ATO-S has a greater conductivity $(20 \mathrm{mS} / \mathrm{cm})$, which is 4 times higher than that of ATO-C. The increased conductivity on ATO-S might be caused by better particle compacting (due to the more uniform particle size distribution) during the pressure-dependent conductivity measurement, or by more oxygen vacancies in smaller particles synthesized by sol-gel method. More studies are needed to explore the origin of the improved conductivity on ATO-S.

Due to the larger specific surface area and higher conductivity, ATO-S demonstrates higher initial capacitance in the CV measurement compared with ATO-C, as shown in Figures $4 \mathrm{~b}$ and $4 \mathrm{c}$. The capacitance of ATO-S loaded on FTO glass remained almost unchanged
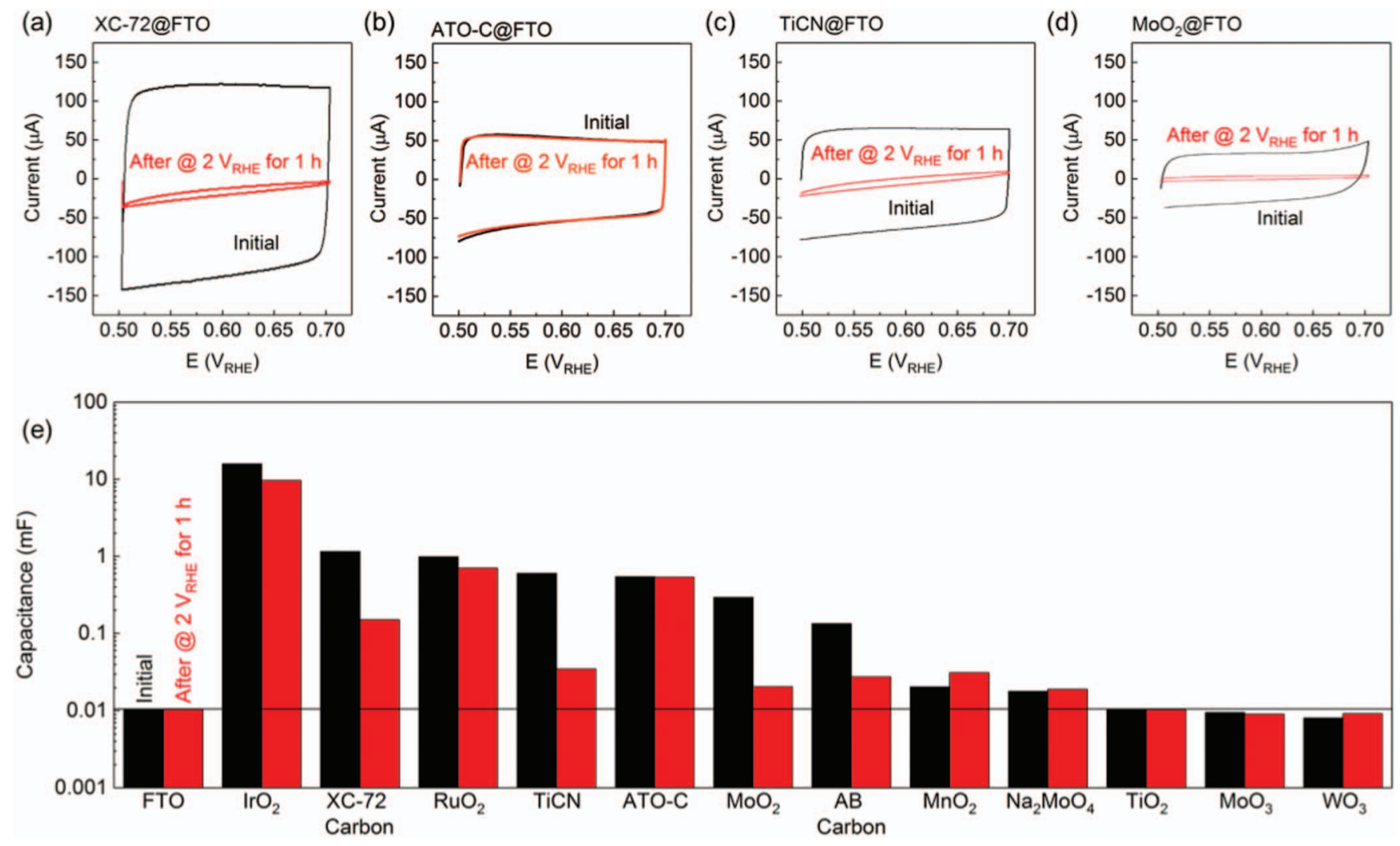

Figure 2. Stability characterization and criteria in material selection. (a)-(d) 4 sets of example $\mathrm{CV}$ curves used for capacitance measurement before and after the holding at $2.0 \mathrm{~V}_{\mathrm{RHE}}$ for $1 \mathrm{~h}$ in Ar-saturated $0.5 \mathrm{M} \mathrm{H}_{2} \mathrm{SO}_{4}$ at $25^{\circ} \mathrm{C}$, for XC-72 carbon, ATO-C, TiCN, and $\mathrm{MoO}_{2}$, respectively. The CV curves were measured at $100 \mathrm{mV} / \mathrm{s}$ between 0.5 and $0.7 \mathrm{~V}_{\mathrm{RHE}}$ in Ar-saturated $0.5 \mathrm{M} \mathrm{H}_{2} \mathrm{SO}_{4}$ at $25^{\circ} \mathrm{C}$. (e) Capacitance before (black) and after (red) the holding voltage at $2.0 \mathrm{~V}_{\mathrm{RHE}}$ for $1 \mathrm{~h}$ in Ar-saturated $0.5 \mathrm{M} \mathrm{H}_{2} \mathrm{SO}_{4}$. The capacitance was calculated using the $\mathrm{CV}$ curves like the examples shown in panels a-d. The horizontal line represents the capacitance of pure FTO glass. All the samples were loaded on the FTO glass with the loading of $100 \mu \mathrm{g} / \mathrm{cm}^{2}$ glass. 
(a)

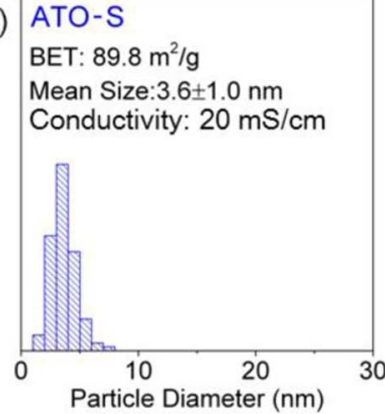

(b)

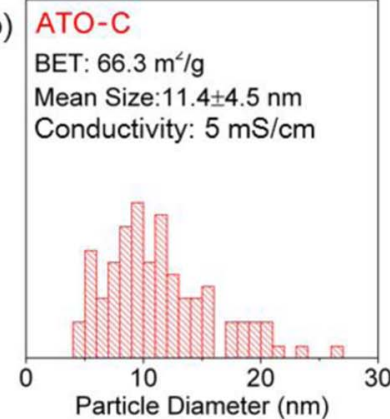

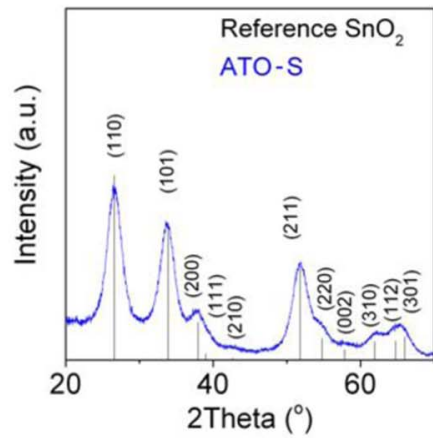

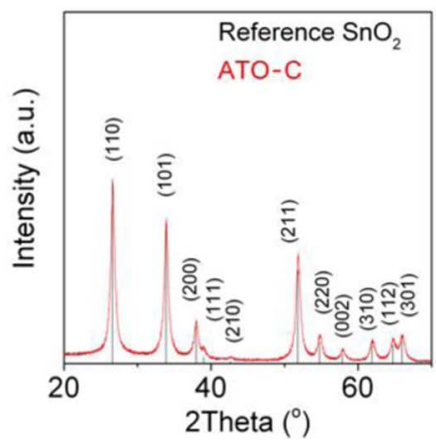

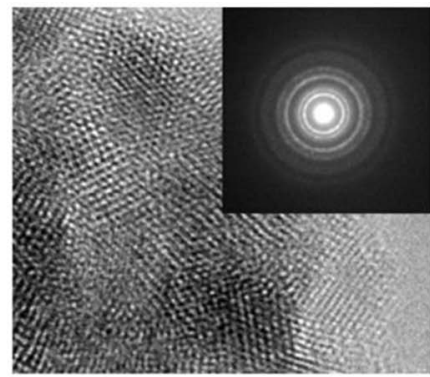

$3 \mathrm{~nm} \quad \mathrm{Sb}:(14.2 \pm 0.6) \%$

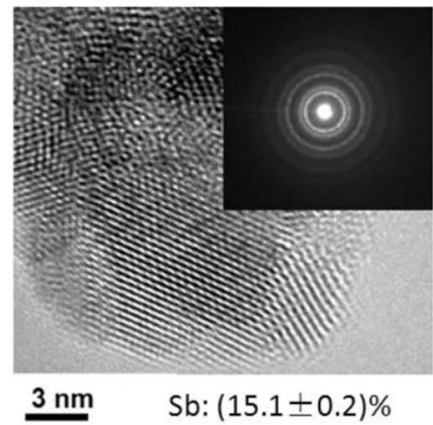

Figure 3. The basic characterizations of (a) sol-gel synthesized ATO (i.e. ATO-S), and (b) commercial ATO (i.e. ATO-C). Left panels: the particle size distributions, BET surface areas, and measured conductivities. The distribution, mean size and standard deviation of ATO particles were measured using TEM images upon over 100 particles. Middle panels: XRD patterns. Both samples showed the same anatase phase. Right panels: TEM images, electron diffraction patterns and EDS-determined Sb concentrations.

(a)
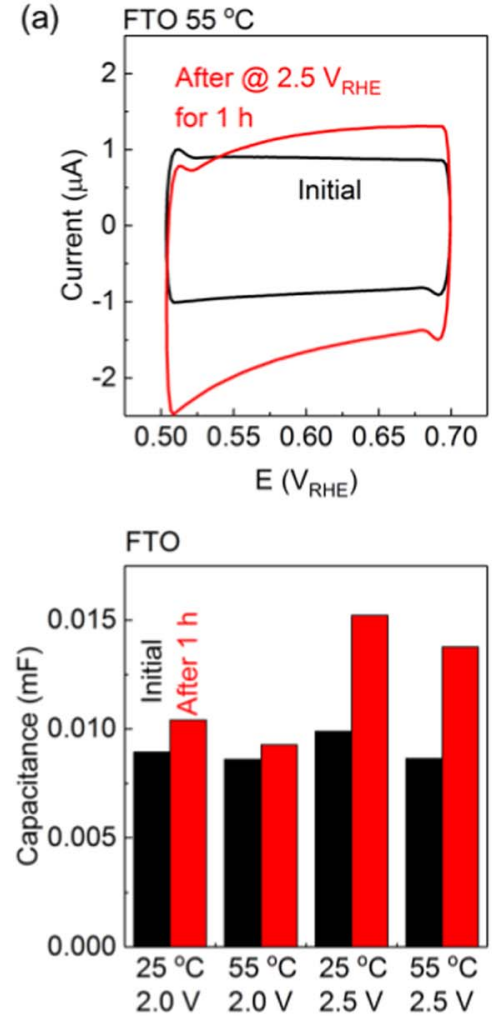

(b)
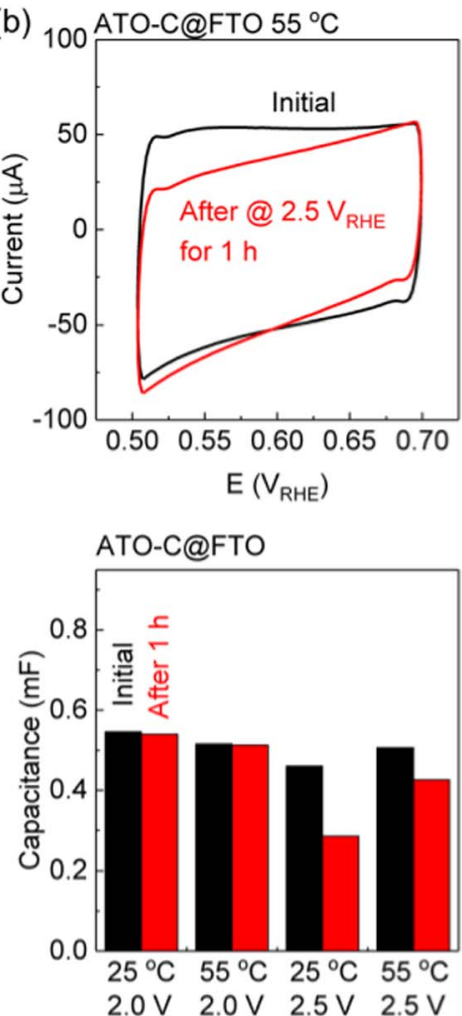
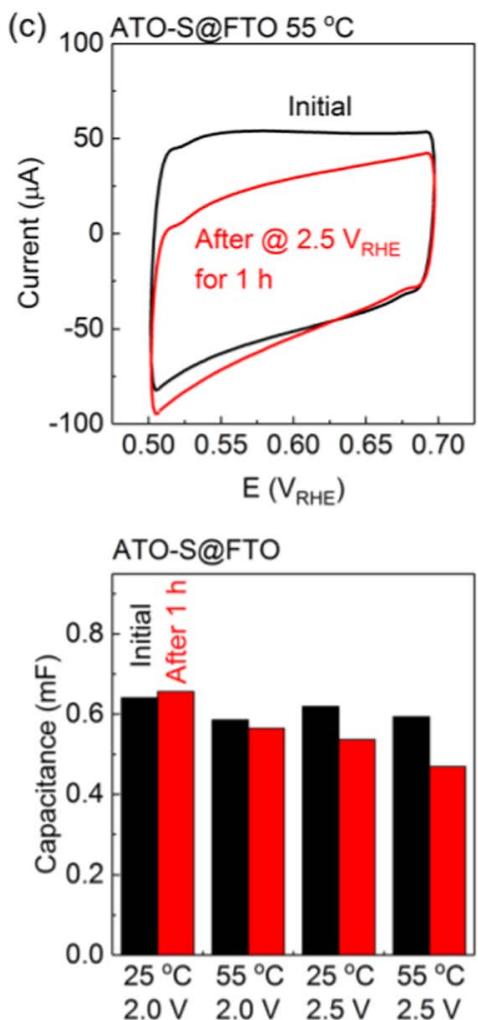

Figure 4. High-voltage and/or high-temperature stability test on (a) FTO glass, (b) ATO-C on FTO glass, and (c) ATO-S on FTO glass. The ATO loadings on the FTO glass were $100 \mu \mathrm{g} / \mathrm{cm}^{2}$ glass. The upper panels showed the example CV curves used for capacitance measurement before and after the holding at $2.5 \mathrm{~V}_{\mathrm{RHE}}$ for $1 \mathrm{~h}$ in Ar-saturated $0.5 \mathrm{M} \mathrm{H}_{2} \mathrm{SO}_{4}$ at $55^{\circ} \mathrm{C}$. The lower panels showed the capacitance calculated from the $\mathrm{CV}$ curves before and after the voltage holding at 2.0 or $2.5 \mathrm{~V}_{\mathrm{RHE}}$ and at 25 or $55^{\circ} \mathrm{C}$ for $1 \mathrm{~h}$ in Ar-saturated $0.5 \mathrm{M} \mathrm{H}_{2} \mathrm{SO}_{4}$. The $\mathrm{CV}$ curves were measured at $100 \mathrm{mV} / \mathrm{s}$ between 0.5 and $0.7 \mathrm{~V} \mathrm{RHE}$ in Ar-saturated $0.5 \mathrm{M}$ $\mathrm{H}_{2} \mathrm{SO}_{4}$. Please notice that the scales of y axes in panel a are different from those in panel b or c, due to the relatively small capacitance of pure FTO glass. 
after keeping the voltage at $2.0 \mathrm{~V}_{\mathrm{RHE}}$ for $1 \mathrm{~h}$, implying it was as stable as the ATO-C samples. To study the stability of ATO material under more severe conditions, we further increased the holding voltage from 2.0 to $2.5 \mathrm{~V}_{\mathrm{RHE}}$, and increased the electrolyte temperature from 25 to $55^{\circ} \mathrm{C}$ (see Figure 4), which is closer to the operating temperature of practical electrolyzers. ${ }^{41}$ When the voltage increased from 2.0 to $2.5 \mathrm{~V}_{\mathrm{RHE}}$, the capacitance of pure FTO glass showed noticeable increase after the voltage holding (see Figure 4a), indicating the more oxidative potential accelerated the surface corrosion of FTO glass. The capacitance change might be caused by the surface roughening during the voltage holding, which could increase the surface area of FTO glass. In comparison, increasing the electrolyte temperature from 25 to $55^{\circ} \mathrm{C}$ showed little influence on the capacitance change of FTO glass, implying that a higher temperature has smaller impact to the stability of FTO during the voltage holding. For the ATO-C and ATO-S powders loaded on FTO glass, increasing the holding voltage from 2.0 to $2.5 \mathrm{~V}_{\mathrm{RHE}}$ at $25^{\circ} \mathrm{C}$ led to a higher capacitance loss, but the capacitance loss of ATO-S was smaller than that of ATO-C (Figures $4 \mathrm{~b}$ and $4 \mathrm{c}$ ). This means the synthesized ATO has higher stability than the commercial ATO under high-voltage conditions at room temperature.
Moreover, when increasing the temperature from 25 to $55^{\circ} \mathrm{C}$, the influence of temperature change on the capacitance stability at $2.0 \mathrm{~V}_{\mathrm{RHE}}$ was still small for both ATO-S and ATO-C, similar to that of pure FTO glass. However, after a higher voltage holding at $2.5 \mathrm{~V}_{\mathrm{RHE}}$, the capacitance loss of ATO-C reduced at the higher temperature of $55^{\circ} \mathrm{C}$. The lower capacitance loss of ATO-C at $55^{\circ} \mathrm{C}$ and $2.5 \mathrm{~V}_{\mathrm{RHE}}$ might be due to the compensation effect from roughening, which increased the specific surface area of the ATO particles and could compensate some of the capacitance loss due to material loss, but further study is required to explain such change.

Electrochemical capacitance and OER measurements of ATO-supported $\mathrm{RuO}_{2}$. - To test the practical supporting performance of ATO particles, we tested the capacitance and OER activity change of $\mathrm{RuO}_{2}$ OER catalysts supported by ATO-C or ATO-S, which was compared with the unsupported $\mathrm{RuO}_{2}$ and $\mathrm{RuO}_{2}$ supported by $\mathrm{AB}$ carbon (Figure 5). All samples were loaded on FTO glass. The loading of $\mathrm{RuO}_{2}$ was $100 \mu \mathrm{g} / \mathrm{cm}^{2}$ glass, and the loading of support material (ATO or carbon) was also $100 \mu \mathrm{g} / \mathrm{cm}^{2}$ glass. After mixing $\mathrm{RuO}_{2}$ with these support materials, the initial total capacitance increased from
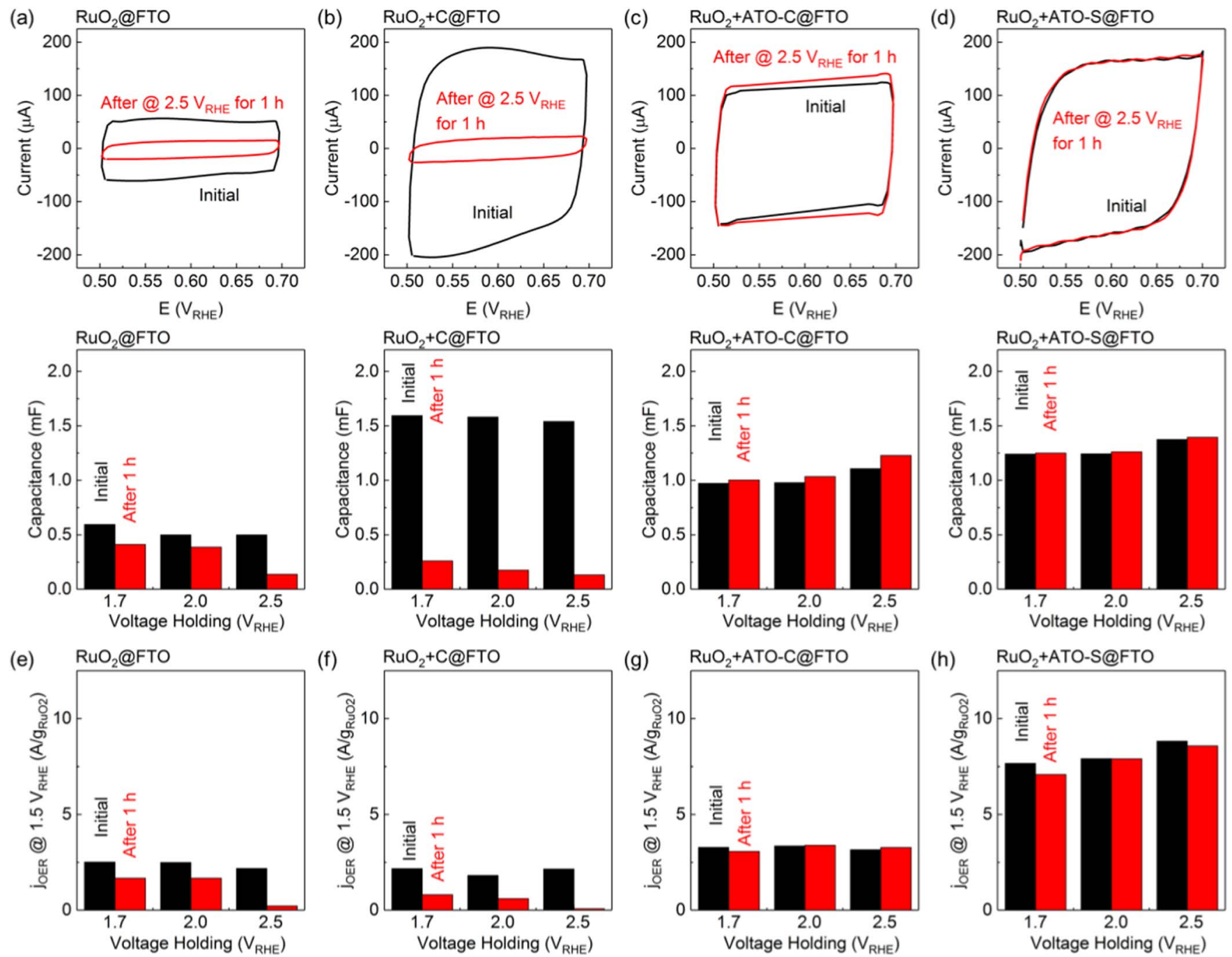

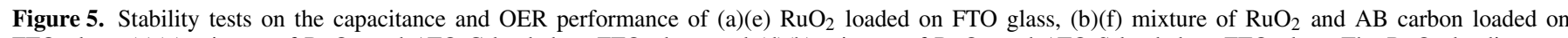

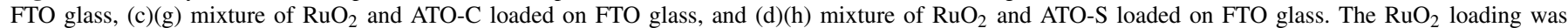

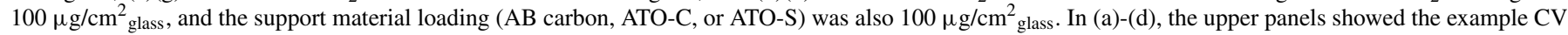

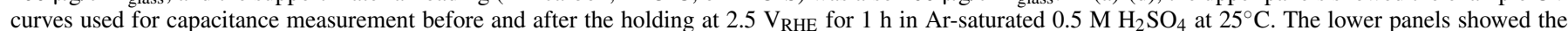

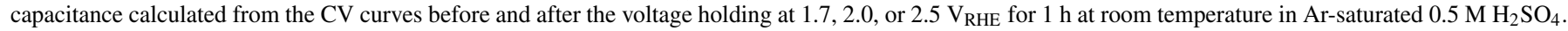

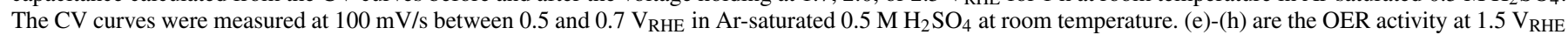
measured before and after keeping the voltage at 1.7, 2.0, or $2.5 \mathrm{~V}_{\mathrm{RHE}}$ for $1 \mathrm{~h}$ at $25^{\circ} \mathrm{C}$ in $\mathrm{Ar}$-saturated $0.5 \mathrm{M} \mathrm{H}_{2} \mathrm{SO}_{4}$. 
$\sim 0.6 \mathrm{mF}$ (no support) to $\sim 1.1 \mathrm{mF}$ (with ATO-C or ATO-S) or $\sim 1.6$ $\mathrm{mF}$ (with carbon), due to the contribution of effective surface areas from the support materials. Meanwhile, the initial OER activity of $\mathrm{RuO}_{2}$ did not deviate much from $\sim 2.5 \mathrm{~A} / \mathrm{g}_{\mathrm{RuO} 2}$ at $1.5 \mathrm{~V}_{\mathrm{RHE}}$ after mixing with the carbon or ATO-C. However, after mixing with the ATO-S particles, the OER activity rose to $\sim 6 \mathrm{~A} / \mathrm{g}_{\mathrm{RuO} 2}$ at $1.5 \mathrm{~V}_{\mathrm{RHE}}$. The improved OER activity could result from a more uniform distribution of $\mathrm{RuO}_{2}$ that increased the effective surface area exposed to the electrolyte. The improvement effect on OER activity of precious-metal oxides at $1.5 \mathrm{~V}_{\mathrm{RHE}}$ brought by the ATO-S in this work ( $\sim 240 \%$ increase) is higher than those of $\mathrm{Ti}_{\mathrm{n}} \mathrm{O}_{2 \mathrm{n}-1}(\sim 200 \%),{ }^{26} \mathrm{SnO}_{2}(\sim 180 \%)^{29}$ and Sb-doped $\mathrm{SnO}_{2}(\sim 190 \%)^{17}$ in previous studies.

When $\mathrm{RuO}_{2}$ is directly loaded on the FTO without any support, after holding at 1.7 or $2.0 \mathrm{~V}_{\mathrm{RHE}}$ for $1 \mathrm{~h}$, the OER activity at $1.5 \mathrm{~V}_{\mathrm{RHE}}$ dropped from $\sim 2.5 \mathrm{~A} / \mathrm{g}_{\mathrm{RuO} 2}$ to $\sim 1.6 \mathrm{~A} / \mathrm{g}_{\mathrm{RuO} 2}$, accompanied with a capacitance drop from $\sim 0.55 \mathrm{mF}$ to $\sim 0.4 \mathrm{mF}$ (Figures $5 \mathrm{a}$ and $5 \mathrm{e}$ ). Both the activity loss and capacitance loss were $\sim 30 \%$, which could be caused by the detachment of $\mathrm{RuO}_{2}$ particles from the FTO glass during the OER process. When the holding voltage was increased to $2.5 \mathrm{~V}_{\mathrm{RHE}}$, a much larger capacitance loss $(\sim 80 \%)$ and activity loss $(\sim 90 \%)$ can be observed after the $1 \mathrm{~h}$ voltage holding. The poor stability observed at $2.5 \mathrm{~V}_{\mathrm{RHE}}$ might be caused by more physical detachments of $\mathrm{RuO}_{2}$ caused by the formation of more $\mathrm{O}_{2}$ gas bubbles and stronger $\mathrm{Ru}$ chemical dissolutions under more oxidative voltages, which have been described in the previous work. ${ }^{35-37,42}$ When $\mathrm{RuO}_{2}$ was mixed with carbon, after holding at 1.7 or $2.0 \mathrm{~V}_{\mathrm{RHE}}$ for $1 \mathrm{~h}$, the OER activity dropped by $\sim 65 \%$ from $\sim 2.0 \mathrm{~A} / \mathrm{g}_{\mathrm{RuO} 2}$ to $\sim 0.7 \mathrm{~A} / \mathrm{g}_{\mathrm{RuO} 2}$, accompanied with a capacitance drop by $\sim 87 \%$ from $\sim 1.55 \mathrm{mF}$ to $\sim 0.2 \mathrm{mF}$ (Figures $5 \mathrm{~b}$ and $5 \mathrm{f}$ ). Both the relative activity loss and relative capacitance loss are much greater than those of the unsupported $\mathrm{RuO}_{2}$ under the same voltage holding condition, indicating that using carbon as the support material could reduce the stability of the system during the OER. The additional capacitance and activity loss compared with the unsupported $\mathrm{RuO}_{2}$ might be caused by the oxidation of carbon support to $\mathrm{CO}_{2}$ in the oxidative OER condition ${ }^{43}$ that leads to the additional detachment of $\mathrm{RuO}_{2}$. When the holding voltage was increased to $2.5 \mathrm{~V}_{\mathrm{RHE}}$, an even larger capacitance loss $(\sim 90 \%)$ and activity loss $(\sim 95 \%)$ were observed, similar to the observation on the unsupported $\mathrm{RuO}_{2}$, which again could be caused by the more severe $\mathrm{RuO}_{2}$ detachment due to the stronger $\mathrm{O}_{2}$ bubble formation or more severe $\mathrm{RuO}_{2}$ dissolution under more oxidative conditions. In contrast, when using ATO-C or ATO-S to support $\mathrm{RuO}_{2}$, no clear capacitance change $(<10 \%)$ or activity change $(<10 \%)$ were observed (Figures $5 \mathrm{c}$, $5 \mathrm{~d}, 5 \mathrm{~g}$, and $5 \mathrm{~h}$ ), even after holding at a high voltage up to $2.5 \mathrm{~V}_{\mathrm{RHE}}$ for $1 \mathrm{~h}$ at $25^{\circ} \mathrm{C}$. The stabilized capacitance and OER activity can be due to the more uniform distribution of $\mathrm{RuO}_{2}$ particles on the electrodes. If the $\mathrm{RuO}_{2}$ particles are not closely packed together, there will be open pathways for the generated $\mathrm{O}_{2}$ gas to leave the surface of $\mathrm{RuO}_{2}$ without detaching the other $\mathrm{RuO}_{2}$ particles during the OER, and therefore will cause less detachment of $\mathrm{RuO}_{2}$ particles. The above observations on the one hand proved the high stability of the ATO particles in acid electrolyte and under the high-voltage condition. On the other hand, it showed that adding stable support materials could help to enhance the stability of the OER performance of $\mathrm{RuO}_{2}$ catalysts, presumably by increasing the distance between $\mathrm{RuO}_{2}$ particles, preventing the particle aggregation, and decreasing the mechanical detachment of catalysts due to the $\mathrm{O}_{2}$ formation. It worth noticing that although in this work $\mathrm{RuO}_{2}$ was used as the model OER catalysts to test the potential beneficial effects from the ATO support, previous studies have shown that ATO support also works for $\mathrm{Ir}^{44}$ and $\mathrm{IrO}_{2}{ }^{33,45}$ during OER catalysis. In fact, the series of selection criteria for support materials explored in this paper should work on general OER catalysts operated in acidic electrolytes.

\section{Conclusions}

In this work, we systematically searched and characterized a series of compounds as the support materials for OER catalysis in acidic electrolytes. The thermodynamic stability criteria and economic cri- teria were discussed and applied to screen the candidate compounds that are potentially cheap and stable enough to be used as the support material for OER catalysis in acidic environment. Then the conductivity and stability tests were used to further optimize the candidate list. Finally, we identified commercial ATO as the most promising candidate support material with reasonable cost, enough conductivity, and high stability in acid electrolyte under the highly oxidative OER potentials. Then we synthesized a nano-sized ATO by sol-gel method, with smaller particle size, larger specific surface area, and higher electrical conductivity compared with the commercial ATO. The newly-synthesized ATO brings greater and more stable improvement of OER activity to the $\mathrm{RuO}_{2}$ catalysts than the commercial ATO and carbon support when used to support $\mathrm{RuO}_{2}$ particles during the OER.

\section{Acknowledgments}

This work made use of the MRSEC Shared Experimental Facilities at MIT, supported by the National Science Foundation under award number DMR-1419807. This work is funded by BASF Inc., USA. The authors want to thank Kaoru Dokko for the discussion on the conductivity measurements, and thank Joseph Elias for the help on material synthesis. The authors declare no competing financial interests.

\section{ORCID}

Binghong Han (D) https://orcid.org/0000-0002-2919-3235

Yang Shao-Horn (10) https://orcid.org/0000-0001-8714-2121

\section{References}

1. H. B. Gray, Nat. Chem., 1, 112 (2009).

2. N. S. Lewis and D. G. Nocera, P. Natl. Acad. Sci., 103, 15729 (2006)

3. M. W. Kanan and D. G. Nocera, Science, 321, 1072 (2008).

4. C. C. L. McCrory, S. Jung, J. C. Peters, and T. F. Jaramillo, J. Am. Chem. Soc., 135 16977 (2013)

5. Y.-C. Lu, Z. Xu, H. A. Gasteiger, S. Chen, K. Hamad-Schifferli, and Y. Shao-Horn, J. Am. Chem. Soc., 132, 12170 (2010).

6. M. Armand and J. M. Tarascon, Nature, 451, 652 (2008).

7. T. Maiyalagan, K. A. Jarvis, S. Therese, P. J. Ferreira, and A. Manthiram, Nat. Commun., 5(3949), 1 (2014).

8. S. W. Lee, C. Carlton, M. Risch, Y. Surendranath, S. Chen, S. Furutsuki, A. Yamada, D. G. Nocera, and Y. Shao-Horn, J. Am. Chem. Soc., 134, 16959 (2012).

9. Y. Lee, J. Suntivich, K. J. May, E. E. Perry, and Y. Shao-Horn, J. Phys. Chem. Lett., 3, 399 (2012).

10. S. Trasatti, J. Electroanal. Chem. Interfacial Electrochem., 111, 125 (1980).

11. K. A. Stoerzinger, M. Risch, J. Suntivich, W. M. Lu, J. Zhou, M. D. Biegalski, H. M. Christen, Ariando, T. Venkatesan, and Y. Shao-Horn, Energ. Environ. Sci., 6, 1582 (2013).

12. J. Suntivich, K. J. May, H. A. Gasteiger, J. B. Goodenough, and Y. Shao-Horn, Science, 334, 1383 (2011)

13. D. B. Meadowcroft, Nature, 226, 847 (1970).

14. M. Carmo, D. L. Fritz, J. Mergel, and D. Stolten, Int. J. Hydrogen Energ., 38, 4901 (2013).

15. R. E. Fuentes, S. Rau, T. Smolinka, and J. W. Weidner, ECS Trans., 28, 23 (2010).

16. L. Zhang, H. B. Wu, and X. W. Lou, J. Am. Chem. Soc., 135, 10664 (2013).

17. J. Xu, Q. Li, M. K. Hansen, E. Christensen, A. L. Tomás García, G. Liu, X. Wang, and N. J. Bjerrum, Int. J. Hydrogen Energ., 37, 18629 (2012).

18. J. W. Long, K. E. Ayers, and D. R. Rolison, J. Electroanal. Chem., 522, 58 (2002).

19. L. Zhang, L. Wang, C. M. B. Holt, B. Zahiri, Z. Li, K. Malek, T. Navessin, M. H. Eikerling, and D. Mitlin, Energ. Environ. Sci., 5, 6156 (2012).

20. H. Yano, T. Akiyama, P. Bele, H. Uchida, and M. Watanabe, Phys. Chem. Chem Phys., 12, 3806 (2010)

21. C.-L. Lee, C.-H. Huang, K.-L. Huang, Y.-L. Tsai, and C.-C. Yang, Carbon, 60, 392 (2013).

22. P. V. Shanahan, L. Xu, C. Liang, M. Waje, S. Dai, and Y. S. Yan, J. Power Sources, 185, 423 (2008)

23. K. J. J. Mayrhofer, J. C. Meier, S. J. Ashton, G. K. H. Wiberg, F. Kraus, M. Hanzlik, and M. Arenz, Electrochemi. Commun., 10, 1144 (2008).

24. S. J. Ashton and M. Arenz, Electrochemi. Commun., 13, 1473 (2011)

25. P. Mazúr, J. Polonský, M. Paidar, and K. Bouzek, Int. J. Hydrogen Energ., 37, 12081 (2012).

26. S. Siracusano, V. Baglio, C. D’Urso, V. Antonucci, and A. S. Aricò, Electrochim. Acta, 54, 6292 (2009)

27. L. Ma, S. Sui, and Y. Zhai, J. Power Sources, 177, 470 (2008).

28. A. V. Nikiforov, A. L. Tomás García, I. M. Petrushina, E. Christensen, and N. J. Bjerrum, Int. J. Hydrogen Energ., 36, 5797 (2011) 
29. J. Xu, G. Liu, J. Li, and X. Wang, Electrochim. Acta, 59, 105 (2012).

30. S. Geiger, O. Kasian, A. M. Mingers, K. J. J. Mayrhofer, and S. Cherevko, Sci. Rep., 7, 4595 (2017).

31. X. Wu and K. Scott, Int. J. Hydrogen Energ., 36, 5806 (2011).

32. A. T. Marshall and R. G. Haverkamp, Electrochim. Acta, 55, 1978 (2010).

33. H.-S. Oh, H. N. Nong, T. Reier, A. Bergmann, M. Gliech, J. Ferreira de Araújo, E. Willinger, R. Schlögl, D. Teschner, and P. Strasser, J. Am. Chem. Soc., 138, 12552 (2016).

34. H.-S. Oh, H. N. Nong, T. Reier, M. Gliech, and P. Strasser, Chem. Sci., 6, 3321 (2015)

35. M. Wohlfahrt-Mehrens and J. Heitbaum, J. Electroanal. Chem. Interfacial Electrochem., 237, 251 (1987).

36. N. Hodnik, P. Jovanovič, A. Pavlišič, B. Jozinović, M. Zorko, M. Bele, V. S. Šelih, M. Šala, S. Hočevar, and M. Gaberšček, J. Phys. Chem. C, 119, 10140 (2015).
37. O. Kasian, S. Geiger, P. Stock, G. Polymeros, B. Breitbach, A. Savan, A. Ludwig, S. Cherevko, and K. J. J. Mayrhofer, J. Electrochem. Soc., 163, F3099 (2016).

38. P. C. K. Vesborg and T. F. Jaramillo, RSC Adv., 2, 7933 (2012).

39. R. W. Rice, Journal of Materials Science, 31, 102 (1996).

40. M. E. Suss, T. F. Baumann, M. A. Worsley, K. A. Rose, T. F. Jaramillo, M. Stadermann, and J. G. Santiago, J. Power Sources, 241, 266 (2013).

41. Ø. Ulleberg, Int. J. Hydrogen Energ., 28, 21 (2003).

42. A. R. Zeradjanin, A. A. Topalov, Q. Van Overmeere, S. Cherevko, X. Chen, E. Ventosa, W. Schuhmann, and K. J. J. Mayrhofer, RSC Adv., 4, 9579 (2014).

43. J. Speder, A. Zana, I. Spanos, J. J. K. Kirkensgaard, K. Mortensen, M. Hanzlik, and M. Arenz, J. Power Sources, 261, 14 (2014).

44. H.-S. Oh, H. N. Nong, T. Reier, M. Gliech, and P. Strasser, Chem. Sci., 6, 3321 (2015).

45. V. K. Puthiyapura, M. Mamlouk, S. Pasupathi, B. G. Pollet, and K. Scott, J. Power Sources, 269, 451 (2014). 